\title{
PEDRO SAINZ RODRÍGUEZ Y LA COMPAÑÍA IBEROAMERICANA DE PUBLICACIONES
}

\section{Pedro Sainz Rodríguez and the Compañía Iberoamericana de Publicaciones}

\author{
ISABEL BALSINDE \\ Fundación Universitaria Española \\ biblio@fuesp.com \\ ORCID ID: 0000-0001-8032-0706
}

Recibido: 14-10-2020 / Aceptado: 10-01-2021 DOI: https://doi.org/10.51743/cilh.vi46.184

RESUMEN

El archivo de Pedro Sainz Rodríguez depositado en la FUE conserva una abundante documentación sobre la Compañía Iberoamericana de Publicaciones (1924-1931), de la que fue su director literario y principal impulsor. La CIAP primó lo pedagógico sobre lo lucrativo, como puede verse en sus colecciones baratas pensadas para la divulgación. No obstante, en su catálogo se incluyeron también textos de investigación dirigidos a eruditos. En la correspondencia conservada podemos conocer las angustias y propuestas de muchos de sus autores.

PALABRAS CLAVE: libro; bibliotecas; imprenta; premios literarios; librerías.

ABSTRACT The files of Pedro Sainz Rodríguez, deposited in the FUE, retain an extensive documentation on the Compañía Iberoamericana de Publicaciones (1924-1931), of which he was the literary director and principal promoter. The CIAP placed the pedagogical aspect above the profit, as can be seen in its cheap informative collections. However, its catalogue also included research texts for scholars. In the correspondence preserved we can learn about the anxieties and proposals of many authors.

KEY WORDS: Book; Libraries; Printing; Literary Awards; Bookshops. 


\title{
PEDRO SAINZ RODRÍGUEZ Y LA COMPAÑÍA IBEROAMERICANA DE PUBLICACIONES
}

\author{
ISABEL BALSINDE \\ Fundación Universitaria Española
}

El ARCHIVO de Pedro Sainz Rodríguez llegó a la Fundación Universitaria Española en 1986. Contiene un fondo documental de enorme relevancia para los estudiosos de cualquier aspecto de la historia de España del pasado siglo XX. Pedro Sainz Rodríguez ${ }^{1}$ (1897-1986) estudió Filosofía y Letras y Derecho en la Universidad Central y en la de Salamanca respectivamente, y a los 23 años obtuvo la cátedra de Lengua y Literatura en la Universidad de Oviedo. Fue diputado en las Cortes de la II República, ministro de Educación Nacional en el primer gobierno de Franco, conspirador monárquico y consejero político de Don Juan en Portugal, a donde se exilió hasta 1969. A su regreso a España se hizo cargo de una cátedra en la Universidad de

\footnotetext{
${ }^{1}$ De su amplia obra, destacamos: Las polémicas sobre la cultura española (1919); Don Bartolomé Gallardo y la crítica literaria de su tiempo (1921); La evolución de las ideas sobre la decadencia española (1924), discurso de apertura del curso académico en la Universidad Complutense de Madrid; Introducción a la historia de la literatura mística en España (1927), Premio Nacional de Literatura; La tradición nacional y el Estado futuro (1935); Menéndez Pelayo y la educación nacional (1938); Menéndez Pelayo, historiador y crítico literario (1956); Espiritualidad española (1961); Un reinado en la sombra (1981); Historia de la crítica literaria en España (1989). A ello hay que sumar sus numerosas introducciones y su actividad al frente de la editorial de la FUE.
} 
Comillas y de la dirección cultural de la Fundación Universitaria Española. Fue además bibliógrafo, erudito especializado en la literatura mística española del Siglo de Oro, que le valió el Premio Nacional de Literatura en 1926, miembro de la Real Academia Española y de la de la Historia, y editor más que notable. A su faceta de editor vamos a dedicar este estudio.

En el archivo de Pedro Sainz Rodríguez (PSR) ${ }^{2}$ encontramos abundante documentación sobre la CIAP (Compañía Iberoamericana de Publicaciones), de la que fue consejero y director literario: «Uno de los momentos de mi actividad que más celebro y más me ha satisfecho es el que desarrollé al frente de la CIAP como director literario de esta editorial» [Sainz Rodríguez, 1978: 124].

\section{LA CIAP}

La Compañía Iberoamericana de Publicaciones se constituyó ante notario el 22 de noviembre de 1924, fruto de un acuerdo entre Manuel Luis Ortega Pichardo, escritor y editor, que ocuparía el cargo de consejero delegado y director gerente, e Ignacio Bauer Landauer, banquero que sería Presidente de su Consejo de Administración. En su primer consejo de administración participaron importantes personalidades de la vida cultural, como el ministro Antonio Goicoechea, el médico y periodista José María Francos Rodríguez o el historiógrafo Rafael Altamira ${ }^{3}$. El catálogo de publicaciones comenzó

\footnotetext{
${ }^{2}$ La mayor parte del archivo de PSR está constituida por su epistolario, que hemos dividido en tres apartados: el primero (1906-1942) llega hasta el exilio en Portugal; el segundo (1942-1968) abarca todo el periodo portugués; el tercero, el regreso a Madrid hasta su fallecimiento en 1986. La correspondencia citada en este artículo procede de la primera parte, y se indica en cada caso la signatura del documento. Además, Julio Escribano y Jerónimo Herrera [2007-2015], colaboradores del Seminario Menéndez Pelayo, han publicado en ocho volúmenes todas las cartas de PSR. Julio Escribano es también autor del libro Pedro Sainz Rodríguez, de la Monarquía a la República [1998].

${ }^{3}$ De todos ellos hay correspondencia en el archivo de Pedro Sainz Rodríguez.
} 
con vacilaciones, con publicaciones de no demasiado interés y con una actividad bastante escasa. Ya en 1927, la CIAP se hace con los fondos de la Editorial Ibero-Africano-Americana y, seis meses después, debido en gran parte a la iniciativa de su nuevo consejero editorial, Pedro Sainz Rodríguez ${ }^{4}$, la empresa comienza su expansión, basada en la adquisición de editoriales ya conocidas como Renacimiento $^{5}$ (fundada en 1910), Mundo Latino (fundada en 1915 y dedicada preferentemente a la publicación de ensayos y traducciones en lengua española de importantes estudios internacionales) y otras de menor alcance como Ediciones Atlántida ${ }^{6}$ y Ediciones Estrella, dirigida esta por Gregorio Martínez Sierra ${ }^{7}$. Estas editoriales que integran la CIAP «se caracterizan por una fisonomía peculiar, viniendo a ser secciones especializadas de un todo orgánico» [Catálogo General CIAP, 1930: 11]. Se compró además el sesenta por ciento de las acciones de las Bibliotecas Populares Cervantes, que fueron para PSR «lo más interesante desde el punto de vista de la difusión de la cultura [...] la mejor colección de índole popular de clásicos españoles y autores extranjeros que se ha publicado en España» [Sainz Rodrí-

${ }^{4}$ La llegada de PSR supuso un «punto de inflexión» [Fuster, 2015: 1]. Pedro Sainz Rodríguez asumió la dirección literaria y él mismo indica su objetivo decidido de dar «una fisonomía coherente a este heterogéneo conjunto editorial que había sido la CIAP hasta la fecha» [Sainz Rodríguez, 1978: 125].

${ }^{5}$ De ella, dice el catálogo de la CIAP de 1930: «La editorial Renacimiento continúa su tradición y edita la casi totalidad de la producción literaria de los autores contemporáneos de España».

${ }^{6}$ Destinada a las publicaciones de índole popular tales como «La novela de hoy», continuadas por «El libro para todos» (que se inició con La guerra carlista, de ValleInclán) y «El libro del pueblo». Enciclopedia popular hispanoamericana. Cuenta con gracia PSR, en Testimonio y recuerdos, que quiso encargarse personalmente de «La novela de hoy» con el fin de «depurarla de una tendencia que hoy en día ha llegado a ser la epidemia de la literatura popular, lo que en aquella época se denominaba literatura verde».

${ }^{7}$ «Biblioteca selecta y completa, donde figuran las obras máximas de la literatura contemporánea. En la elección [...] se tienen en cuenta motivos artísticos, excelencias literarias, encantos singulares, que son los que más estima el lector de sensibilidad experimentada» [Catálogo General CIAP, 1928]. 
guez, 1978: 133], que contaban con dos series «Las cien mejores obras de la literatura española» y «Las cien mejores obras de la literatura universal», y La Gaceta literaria, de aparición quincenal, fundada en 1927 por Ernesto Giménez Caballero, y codirigida con él a partir de 1929 por Pedro Sainz Rodríguez. Sobre ella se nos informa:

La CIAP la cobija bajo su pabellón, cediéndola su independencia literaria de siempre $[\ldots]$. Es la única revista española que informa con amplitud del movimiento literario de España, del resto de Europa y de América. [Con ella] se consigue estar al tanto de la última novedad literaria, del último acontecimiento importante de la cultura universal [...]. Asistida de un espíritu integral, amplísimo, que le permite reunir en sus páginas las colaboraciones más distintas, los escritores de más opuesta significación, pero siempre de un mismo espíritu de selección y pureza artística y literaria [Sainz Rodríguez, 1978: 133] .

A la sazón, la CIAP adquirió también una agencia de noticias, una empresa de huecograbado, una fábrica de tintas y una moderna imprenta (la Compañía General de Artes Gráficas), con sus correspondientes almacenes, pensados para albergar de cuatro a cinco millones de volúmenes ${ }^{9}$. Compró además la Librería Fernando Fé (con diez establecimientos), situada en la Puerta del Sol, por aquel entonces la mayor distribuidora de España. Se proyectó e inició la creación de delegaciones en Buenos Aires, Montevideo, México y Quito. La CIAP y sus instalaciones se establecieron en un edificio «de cincuen-

\footnotetext{
${ }^{8}$ La Gaceta literaria (1927-1932), contó con Guillermo de Torre como su secretario, y con la colaboración de Luis Buñuel, Rafael Alberti, Benjamín Jarnés, Ramiro Ledesma Ramos, Luis Araquistáin, Ramón Gómez de la Serna, José Moreno Villa, José Bergamín, Salvador Dalí o Federico García Lorca, entre otros muchos. Considerada como la plataforma del movimiento vanguardista español, no perdió su carácter cuando fue adquirida por la CIAP.

${ }^{9}$ «Si las circunstancias no hubieran impedido llegar al total desarrollo del plan trazado, hubiéramos ido a la creación de una fábrica de papel, logrando con ello reunir todos los elementos que intervienen en la industria del libro, abaratándonos la producción y colocándonos en condiciones excepcionales frente a la competencia». [Cómo se ha hecho una gran empresa editorial y cómo pretenden deshacerla [1932]: 24].
} 
ta mil pies de extensión y con unas construcciones excelentes» en los números 42 y 44 de la calle de Príncipe de Vergara nada menos. Para obtener mayor rendimiento económico, creó también una agencia de prensa encargada de comercializar sus artículos, cuyo servicio contrataron muchos periódicos españoles de provincias y seis de Hispanoamérica [Santonja, 1989: 15].

A través de sus extensos catálogos editoriales, podemos conocer las colecciones que integraron la CIAP, descritas del modo siguiente. La Colección de Documentos inéditos para la Historia de Hispanoamérica, dirigida por Rafael Altamira, «ofrece a los investigadores [...] los elementos históricos antes ignorados en los archivos». Pretende igualmente constituir «la obra más eficaz de vindicación histórica que a la labor de España en el Nuevo Mundo se ha dedicado». Las Fuentes narrativas de la historia de Hispanoamérica, bajo la dirección de PSR, «facilitan la lectura de los rarísimos libros de la primitiva historiografía americana». La biblioteca de Monografías Hispanoamericanas, también a cargo de Altamira, «presenta ya elaborados por investigadores modernos verdaderos capítulos de la historia americana». La Historia de América y de la civilización hispanoamericana es «uno de los esfuerzos más grandes emprendidos por la CIAP, con el que se propone satisfacer una verdadera necesidad de la historiografía mundial», dirigida por Antonio Ballesteros Beretta. Las Bibliotecas Populares Cervantes, dirigidas por el inspector de primera enseñanza Francisco Carrillo Guerrero, «han realizado el milagro de llevar a un precio inverosímil, por lo barato, ediciones de las obras maestras de la literatura a las manos más humildes». Los clásicos olvidados «viene a continuar y a completar los grandes esfuerzos de la erudición española del pasado siglo, exhumando en bellos libros, científicamente trabajados, los enormes tesoros todavía ignorados o preteridos de nuestra riquísima literatura nacional». La Biblioteca Nebrija «está destinada a completar este programa publicando textos correctos y traducciones exactas y bellas de los clásicos latinos».

La CIAP considera complemento indispensable en su divulgación 
de la literatura universal el conocimiento de las dos grandes literaturas peninsulares no escritas en castellano, «y a ello están destinadas dos importantes colecciones, la Biblioteca Camoens y la Biblioteca Catalana, acogidas al sello editorial Mundo Latino ${ }^{10}$.

A estas colecciones se suman otras en su afán por mostrarse «enterados de los progresos realizados en otros países y, [porque] sobre todo, deseamos evitar a todo trance el peligro gravísimo de que la cultura clásica [...] llegue a España, y especialmente a las naciones americanas $[. .$.$] por otros cauces distintos de la lengua común y ela-$ borados con espíritu diferente al de nuestra civilización [...]. La marcha cultural de un pueblo debe ser un equilibrio entre la tradición y el progreso [...]». Cuatro colecciones se orientan en este sentido: «Investigación y crítica; Biblioteca del Hispanismo; Ciencia, Filosofía, Cultura, Biblioteca del pensamiento moderno» (dirigida por Eugenio d'Ors ${ }^{11}$ ) y «El mundo de hoy, Biblioteca del hombre moderno", que "pretende recoger todas las palpitaciones de la actualidad política, social y económica del momento actual». Además, aparecen en el catálogo todas las obras publicadas por la Real Academia de la Historia.

En noviembre de 1930 surge la sorprendente colección Ediciones hoy, con unos planteamientos ideológicos muy diferentes a los de la CIAP, que Santonja atribuye a «la lógica expansiva inherente a cualquier empeño monopolista» [1989: 104]. Así lo consigna Rafael Marquina en su reseña para La Libertad [1 de noviembre de 1933 $]^{12}$ :

\footnotetext{
${ }^{10}$ Entre sus autores portugueses, Ferreira de Castro o Fidelino de Figueiredo; entre los catalanes, Carles Riba, Josep Pla, José María Capdevilla, José María de Segarra, Josep Carner, Apeles Mestres o Luis Nicolau d'Olwer.

${ }^{11}$ Eugenio d'Ors colaboró además con la editorial publicando en ella toda su obra, y planeó otras colecciones de notable interés como Monitor de Arte, Cultura, Estética y Vida Estética.

${ }^{12}$ La Libertad [1919-1939] fue un periódico madrileño de carácter progresista y amena lectura, entre cuyos colaboradores figuraron los redactores Pedro de Répide, Augusto Barcia y Manuel Machado, y el célebre fotógrafo Alfonso.
} 
Literatura de última hora que vive y se nutre de las grandes preocupaciones fundamentales de nuestro tiempo, y de la realidad actual toma los elementos con que contribuir a la formación de una Humanidad nueva [...]. Hemos querido señalar con júbilo la aparición de esta Editorial, que quizás precisamente por ser literalmente de izquierda atiene a todo lo humanamente central.

Hasta el verano de 1931, manteniendo un ritmo de publicación quincenal, salieron 19 obras de autores como John Reed, Andrés Nin, Victor Serge o León Trotski, con traducciones de Francisco Ayala, Juan Rejano o Manuel Pumarega.

Además de La Gaceta literaria, la CIAP poseyó otras publicaciones periódicas. La Revista de la Raza (con colaboraciones de Ángel Pulido, Rafael Altamira, Carmen de Burgos, Alejandro Lerroux, Ramón Otero Pedrayo, Esteban Salazar Chapela, Niceto Alcalá-Zamora o José Antonio de Sangróniz, entre otros) se anunciaba del modo siguiente:

Revista pública de informaciones destinada a la mujer, al niño, al hogar [...]. Recoge todos los aspectos, todos los motivos de la existencia, todas las dimensiones de la cultura -la política, el teatro, el cinema, la literatura, la vida universitaria, etc.- y con tan complejos elementos ofrece quincenalmente una información integral de todo cuanto acontece en el mundo, particularmente en España.

También el Heraldo de Marruecos, diario dirigido por Agustín Aguilar y Tejera; la Bibliographia medica chirurgica, de aparición quincenal; Cosmópolis, mensual con colaboraciones de Martínez Sierra, Salazar Chapela, Antonio Robles o Tenreiro, «destinada al gran mundo, a la vida elegante y aristocrática [...] la publicación mensual española de mayor importancia [...] [que] atiende a todas las direcciones de la cultura, de los acontecimientos, de las informaciones mundiales, de la actualidad, del pasado y del porvenir»; El perro, el ratón y el gato, «semanario de las niñas, de los chicos, los bichos y las muñecas; el mejor semanario infantil de España»; y Libros, «único boletín que se 
publica en España con una bibliografía completa, al día, de la producción mensual de España y América».

La CIAP tampoco escatimó esfuerzos en sus minuciosos y eruditos catálogos editoriales. En el de 1930, de 319 páginas, se incluye una introducción en varios idiomas (alemán, inglés, francés, italiano, portugués y catalán, además del castellano). Aparecen ilustraciones (retratos, portadas y paisajes, algunos a todo color) ${ }^{13}$. Se había editado otro más pequeño, de 69 páginas, en 1928, pero igualmente ilustrado. No se trató de simples anuncios de libros, pues publicaba reseñas críticas de muchos de sus autores, con selecciones de textos referidos a ellos.

La editorial surgió con afán educador, que pareció primar sobre el beneficio económico, dando gran importancia a la lengua española y su difusión en Hispanoamérica:

Es lamentable que las obras maestras de la literatura rusa, alemana, inglesa y tantas otras, sean conocidas en el mundo de habla española por medio de traducciones francesas y con un retraso inconcebible. Es necesario lograr que el instrumento normal de comunicación de los países americanos con la cultura europea contemporánea sea la edición española y la lengua madre.

Podemos, por tanto, hablar del mayor grupo editorial de España y Latinoamérica. Por cinco pesetas al mes, se podían recibir por suscripción: 4 números de La Raza, 4 números de El perro, el ratón y el gato, 4 números de «La novela de hoy», 2 números de La Gaceta literaria, 1 número de Cosmópolis y 1 número de Libros. Además, la CIAP puso en práctica ideas muy modernas, como la venta de libros a plazos, cuyas condiciones aparecen explicadas en sus catálogos editoriales.

Sus numerosas librerías son calificadas como «deliciosos departamentos de cultura, así por el número y la diversidad de sus volúmenes como por la pulcritud y singularidad estética de su instalación y

\footnotetext{
${ }^{13}$ La propia empresa se enorgullece de ello: «Este Catálogo general, en el que se reseñan todos sus fondos y colecciones, es sin disputa, por su extensión y calidad, el repertorio más copioso de la actual producción histórica y literaria de España».
} 
ornamentación». Estaban en Madrid, Barcelona, Sevilla, Cartagena, La Coruña, Cuenca, Jerez, San Sebastián, Zaragoza. Y en Buenos Aires. Ángel Dotor aduce:

Las ventas de estos establecimientos son considerables, lo que quiere decir que ejercen influencia cultural en el despertar español del momento [...]. Sus medios de información bibliográfica, admirables por el desinterés, la acuidad y la prontitud que los presiden; el inmejorable servicio de pedidos, hasta de aquellos libros que aun hace pocos años era imposible adquirir en Madrid y tantos otros detalles más, hacen que merezca señalar su importante existencia, sin regateo de aplauso y elogio por parte de cuantos ambicionamos el verdadero resurgimiento español [Libros, noviembre 1939: 3].

Además, para contribuir a una mayor difusión de la colección de las Bibliotecas Populares Cervantes, se organizaron bibliotecas en las ciudades pequeñas, en las que se nombraba a delegados de la editorial encargados de su buen funcionamiento.

López-Morell esgrime cinco innovaciones fundamentales para el éxito de la CIAP: las nuevas relaciones entre autor y editor, dignificando el oficio del primero a través de sus contratos; las nuevas técnicas de marketing y publicidad; la red de librerías; la Asociación El Mejor Libro del Mes (creada en 1923 dentro de las actividades de la CIAP); y la internacionalización del mercado [López-Morell, 2012: 122-125]. Sin duda la actividad de Pedro Sainz Rodríguez fue fundamental en todo ello, debido a sus contactos y conocimientos del mundo del libro y la bibliografía. Y así se refleja en las numerosas cartas que se conservan en la FUE.

Además, la Compañía editorial organizaba fiestas, que suponían una publicidad importante en aquel entonces. Así, por ejemplo, en Madrid, el Día del Libro en el Círculo de Bellas Artes, los banquetes literarios en Lhardy, el Día de Reyes (con reparto de juguetes y libros a los hijos de los empleados, y asistencia de miembros de la CIAP, como Artiles, Salazar y Chapela, Blasco Fombona y otros, y con ellos siempre Pedro Sainz Rodríguez) o las Semanas del Libro. 
A Pedro Sainz Rodríguez se debió el considerable aumento de la nómina de autores, muchos de los cuales escribirían sus obras en exclusiva para la editorial a cambio de un sueldo fijo, establecido según sus ventas: Manuel Azaña, Azorín, Ricardo Baroja, Antonio Ballesteros Beretta, Eduardo Barriobero, Rufino Blanco Fombona, Carmen de Burgos, Francisco Cossío, Eugenio d'Ors, Rubén Darío, Concha Espina, Wenceslao Fernández Flórez, José María Gabriel y Galán, Ernesto Giménez Caballero, Ramón Gómez de la Serna, Alberto Insúa, Juan Ramón Jiménez, Salvador de Madariaga, Gregorio Marañón, Gregorio Martínez Sierra, los hermanos Machado, Gabriel Miró, Pedro Salinas, Miguel de Unamuno y Ramón del Valle-Inclán, entre otros muchos. De hecho, la CIAP considera

que el elemento fundamental de la producción literaria es el autor, y no ha perdonado esfuerzo ni sacrificio para trabajar por la mejora de su situación moral y material. Los banquetes periódicos de la CIAP han venido a sustituir en España a la organización del PEN Club, que en otros países funciona y ha logrado establecer verdaderos hábitos de camaradería y convivencia entre autores distanciados [...]. Sin duda, la empresa editorial podía enorgullecerse de ser un campo neutral donde conviven escritores de los más opuestos idearios, procurando implantar hábitos de comprensión y tolerancia, también desacostumbrados en nuestros medios intelectuales [Catálogo general CIAP, 1930: 11-12].

La editorial inició su decadencia en 1931, en gran parte debido a sus problemas económicos, y acabó en quiebra. Tuvo que vender todo su fondo a precios de saldo y en julio suspendió oficialmente los pagos. Se redujeron las tiradas y se cancelaron los proyectos. El proceso se alargaría casi diez años. Una buena parte de la correspondencia que se conserva en la FUE se refiere a reclamaciones de liquidaciones por parte de los autores.

Hacia 1932 aparece un folleto sin indicación de autor, aunque probablemente fuera obra de Manuel Ortega Pichardo, con el título Cómo se ha hecho una gran empresa editorial y cómo pretenden deshacerla, 
publicado por la CIAP, en un último intento de salvar lo irrecuperable. El título va encabezado por el lema: Por los intereses de la cultura. Tras una introducción sobre la historia de la CIAP y su desarrollo, se explica el capital de la editorial y sus relaciones con la Casa Bauer y Compañía, su inversora. A continuación, la suspensión de pagos y el proceso judicial. Hay en este folleto un apartado, «Los escritores españoles están con la CIAP», del que, por su interés, vamos a reproducir la mayor parte:

No podemos permanecer indiferentes los escritores en el arreglo de las circunstancias por que atraviesa de momento la CIAP. El hecho de que la Casa editorial donde agrupamos nuestra producción y tenemos nuestro pan asegurado altere su economía o la vea en peligro, sería suficiente para justificar nuestra inmediata intervención en la disputa [...]. Pero nosotros, los artistas, no nos pronunciamos [...] en nombre de nuestros intereses crematísticos, sino de nuestros intereses espirituales [...].

Todavía más importante que cualquier propiedad de sola expresión mercantil es la que contribuye al progreso de la cultura, a la afinación de la sensibilidad o del gusto, al perfeccionamiento de la parte divina del hombre, de sus dotes mentales y de su cultura ética. Una biblioteca, un periódico, un teatro, una escuela, un museo, un laboratorio, son entidades por encima de intereses particulares [...]. En el mismo caso se considera a la Editorial cuando es taller de inteligencia y sembradora y alumbradora de riqueza intelectual. La Casa editorial no está formada en su íntima realidad por la mecánica de sus oficinas, imprentas y librerías; es una reunión de escritores la que forma su núcleo vivo, la sostiene y propaga [...].

Nosotros podemos decir en pura verdad que somos la Compañía Iberoamericana de Publicaciones. Sin nosotros la CIAP podrá tener organización, empleados, papel, maquinaria para imprimir y despachos para vender libros; pero no tendrá libros [...]. Nosotros somos la CIAP, y en las incidencias surgidas entre ella y sus financieros, nos personamos para decir:

1. No estamos dispuestos a consentir que se nos trate como mercancía y se hagan transacciones a espaldas nuestras [...]. Somos dueños de nuestra obra y libres en el porvenir $[\ldots]$ 
2. La labor de la CIAP en su aspecto cultural, en los escasos tres años de su existencia ${ }^{14}$, nos parece admirable germen de cosecha fructífera, cumplidora de esa generosa función social a que antes aludimos. Por tanto, nos solidarizamos con ella. Ha elevado el nivel económico del escritor; difundido sus obras en términos aquí no alcanzados hasta ahora; ha creado numerosísimos centros de venta; ha reunido a los escritores americanos con los españoles; roto las mezquinas normas tradicionales; puesto los jalones de una colosal propagación del libro; ha servido a los lectores selectos en calidad y baratura; satisface la noble pasión del saber con la creación de colecciones que colman los anhelos populares. Un esfuerzo tan considerable y bien orientado, por fuerza ha de merecer nuestra adhesión entusiasta.

3. La labor de la CIAP ha constituido la mayor influencia de España y de su idioma en el estado internacional, singularmente en Hispanoamérica. La CIAP merece la atención del Estado, y la solicitaremos si llega el oportuno momento; y

4. No debe malograrse el trabajo magnífico que ha realizado la CIAP, ni sus proyectos para el futuro; no debe interrumpirse su plan, en gran parte establecido [...]. Y nosotros prometeremos a la CIAP la exclusiva de nuestra creación, siempre que la Compañía continúe sus actividades con el mismo carácter.

Los escritores hispanoamericanos reunidos en la CIAP deseamos que en el arreglo del aspecto económico de la Empresa pesen nuestras consideraciones, motivadas por la defensa de otro aspecto de la Compañía, el espiritual, $\mathrm{y}$, unidos todos, podamos continuar con el mismo entusiasmo la magna labor de propagar el libro, signo supremo de la civilización ${ }^{15}$.

\footnotetext{
${ }^{14}$ Aunque la editorial se fundó en 1924, su actividad relevante no comienza hasta 1927, año en que PSR asume la dirección literaria.

${ }^{15}$ El texto está firmado por más de cincuenta destacados autores, entre ellos: Valle-Inclán, Marañón, Azorín, Fernández Flórez, Antonio y Manuel Machado, Carmen de Burgos, Eduardo Zamacois, Concha Espina, Francisco Camba y Alberto Insúa.
} 


\section{LA CIAP EN EL ARCHIVO DE LA FUNDACIÓN UNIVERSITARIA ESPAÑOLA}

La primera constancia de la existencia de la CIAP en el Archivo PSR es una carta de Ignacio Bauer [PSR1/3-516] nombrando a Pedro Sainz Rodríguez consejero en Madrid, a 19 de agosto de 1927, en la que califica su empresa como «la realización de un ideal de cultura y de patriotismo». A partir de entonces, la correspondencia con Manuel Luis Ortega Pichardo, su consejero delegado y director gerente, será constante y fluida, y la actividad del catedrático, casi desenfrenada. Se le consulta sobre publicaciones, sobre diseño de papel y cubiertas, sobre folletos publicitarios, etc. En septiembre de ese mismo año se inicia la celebrada colección «Los clásicos olvidados» en estrecha colaboración con PSR, que la dirigirá. En ese año y los dos siguientes, son numerosos también los eruditos que brindan sus sugerencias: entre ellos, Ángel Valbuena [PSR1/4-68], que presenta una edición de dramáticos del siglo XVIII, con obras de Cuéllar (El pastelero de Madrigal), o de Matos, Moreto y Cáncer (La adúltera penitente); Claudio Sánchez-Albornoz [PSR1/5-243] que sugiere las cartas sobre España de Blanco-White; Luis Araquistáin [PSR1/5-473] que plantea la edición de las obras de H.W. Schneider, Formación del estado fascista, y de Salvador de Madariaga, La jirafa sagrada; o Maurice Delamain [PSR1/6-341], de la Librairie Stock, quien, a instancias de Esterlich, apunta la obra de Romain Rolland, Vie de Ramakrisna y su continuación. Otros, como Manuel de Montoliú o Azorín, proponen traducciones. Muchos rinden su colaboración, como Pere Bohigas, Vicente Huidobro, Rafael Cansinos-Assens, José María Albiñana, entregando su propia obra o bien estudios o versiones de ediciones reconocidas. A este respecto, el 28 de agosto de 1928, dice Ortega [PSR1/4-498]:

A Azorín creo que debe Ud. contestarle ofreciéndole la publicación de esas obras por la Compañía. Es una excelente adquisición. Hay que evitar que se vaya Wenceslao. Con su dialéctica, convénzalo de que pernocte con no- 
sotros. Dígale que se le abonará cuanto se le adeuda en Atlántida [...]. Un abrazo de su buen amigo, que no le quiere.

Existe mucha correspondencia con Manuel Ortega Pichardo. En muchas de las cartas se convoca a PSR a jornadas de trabajo para la celebración de congresos, como el de Hispanistas, y otras actividades, en su calidad de miembro del Patronato de las Bibliotecas Populares Hispano-Americanas. En otros casos se dirige a PSR solicitándole información sobre posibles ediciones o para pedirle consejo sobre diseños editoriales, así como para enviarle pruebas de imprenta.

\section{«LOS CLÁSICOS OLVIDADOS»}

La colección «Los clásicos olvidados», que lleva por subtítulo «Nueva Biblioteca de Autores Españoles», podría considerarse el buque insignia de la CIAP. Dirigida por PSR, sigue la idea iniciada por Menéndez Pelayo para la editorial Bailly-Baillière, que pretendió continuar la obra de Rivadeneyra, si bien completándola y corrigiendo sus posibles deficiencias. Sobre esta valiosa colección conservamos numerosas cartas, de las que solo podemos seleccionar algunas.

El 1 de marzo de 1928, Gerardo Diego [PSR1/4-245] expone:

He leído el prospecto de Clásicos olvidados. Me parece muy bien y espero que nos pondremos de acuerdo para hacer yo algún tomo. ¿Cuáles son las condiciones económicas y el tamaño?» El 20 de marzo de 1928 [PSR1/4278] acepta la delegación comercial en Asturias «aunque por adelantado me confieso inhábil y pesimista; pero, en fin, se hará lo que se pueda [...]. Encantado de colaborar con los clásicos. Por ahora no tengo tiempo; pero en el otoño, a la vuelta de América elegiré algún o algunos textos.

Por su parte, Antoni Rubió i Lluch [PSR1/4-253] informa el 5 de marzo de 1928:

He recibido el prospecto de su nueva Biblioteca y por lo pronto he suscrito a ella mi Facultad [...]. Entre los tomos ofrecidos los hay muy interesantes. Dichoso el que pueda leerlos. No puedo prometerle más ancho campo de 
propaganda porque aquí por desgracia no hay mucho ambiente para tales empresas que honran su buen gusto y actividad.

Pedro Aguayo Bleye [PSR1/4-272], el 15 de marzo de 1928, indica:

Ayer llegó un paquete con una veintena de prospectos de Los clásicos olvidados. Soy un pésimo comerciante, pero desde luego me parecen pocos los 20 prospectos contratos [...]. Dentro de dos o tres días sale a recorrer la provincia un viajante de libros a la comisión, que me visita alguna vez y le daré algunos contratos. Renuncio por mi parte a toda comisión en los contratos que dicho señor pueda hacer. Luego buscaré algún otro colaborador permanente. En Bilbao espero hacer muy pronto algunos clientes...

Azorín [PSR1/4-334], el 7 de mayo del mismo año, comenta que desearía colaborar, pero le es imposible.

El 9 de junio de 1928, Jorge Guillén [PSR1/4-397] se compromete también a difundir la colección.

Por estas fechas, PSR hace su interpelación en la Asamblea Nacional, relativa a la reforma del plan de estudios de la enseñanza secundaria, lo que da lugar a una abundante correspondencia al respecto por parte de los colaboradores de la CIAP.

Eduardo Gómez Baquero [PSR1/4-487] redactará un artículo muy laudatorio en El Sol sobre Los clásicos olvidados, y María Sánchez Arbós [PSR1/4-488] alude a ello. El artículo tiene fecha de 21 de agosto de 1928. Entre otras cosas, podemos leer:

La novedad que veo en esta colección [...] consiste en que se sitúa entre las colectáneas de bibliófilos que buscan los documentos literarios raros y las bibliotecas generales de clásicos que reúnen los modelos de la lengua y del arte literario, sin guiarse solo por el criterio de la rareza o la escasez del texto impreso. A juzgar por los volúmenes publicados, preside en la nueva biblioteca un discreto criterio ecléctico que va desde la edición paleográfica, cuando el texto lo requiere, a la reimpresión esmerada de libros notables que no figuran en las colecciones anteriores [...]. Dirige la colección [...] Pedro Sainz Rodríguez [...] uno de los eruditos y críticos mejor dotados para continuar la obra de Menéndez Pelayo y de su discípulo Bonilla San Martín [...]. El peligro para lo mucho que promete Sainz Rodríguez está 
en que se disemine demasiado su esfuerzo, en que los viajes a otras zonas de la actividad lo alejen de la especialización literaria [...]. No habría mal, sino posibles ventajas, en que un hombre culto e inteligente, que conoce muy bien la enseñanza como el Sr. Sainz Rodríguez, fuera ministro en un medio político normalizado que pudiera prometerse un mañana. Pero sí habría lesión notoria y daño no compensable en que sus grandes posibilidades de erudito, historiador y crítico no dieran todo el rendimiento que prometen por la competencia de otras preocupaciones y cuidados.

Premonitorio sin duda.

\section{LOS AUTORES Y SUS CIRCUNSTANCIAS}

La correspondencia con los autores se centra sobre todo en las condiciones económicas, si bien encontramos también enfados, felicitaciones, propuestas, solicitudes de ayuda o comentarios literarios.

El 23 de junio de 1928, Azorín [PSR1/4-417] rechaza la invitación de Ignacio Bauer y PSR por haber sido expulsado de la Asociación de la Prensa por Francos Rodríguez, vicepresidente de la CIAP, debido a una cuestión de opiniones en el estreno de su obra El clamor, en el teatro de la Comedia de Madrid:

El indicado señor [Francos Rodríguez] es posible que concurra, y yo, que he sido expulsado por indigno de la Asociación de la Prensa, no quiero sentarme a la misma mesa que esa persona. En un país civilizado, en una nación europea, en el siglo XX, un exministro liberal firma una sentencia condenatoria por supuestos delitos de opinión; no seré yo, la víctima, quien legitime de cualquier modo ese acto de reaccionarismo y de barbarie.

Luis Araquistáin [PSR1/5-70], el 6 de octubre de 1928, notifica: «Le confirmo por escrito mi acuerdo con todo lo que hablamos y mi satisfacción de poderme asociar a una Empresa moderna que tiene al frente espíritus tan ágiles como el suyo, llenos de iniciativas propias y tan sensibles a las ajenas». Propone también que se le pague una cuota mensual de 1000 pesetas en vez de anticipos o liquidaciones trimestrales, lo que le permitiría «poder liberarme de la casi diaria labor 
periodística para consagrarme casi íntegramente al libro. Digo casi porque tampoco conviene abandonar del todo los periódicos, especialmente cuando tanto pueden servirnos para nuestros planes editoriales... Usted me entiende».

Emilio Gutiérrez-Gamero [PSR1/5-123], el 5 de noviembre, cuenta las posibilidades de contrato:

Hay dos formas de contratar con las editoriales, una que consiste en la venta de la primera edición de la obra a cambio de un tanto alzado que el autor recibe, y otra mediante la cual la empresa editorial se reserva cierto número de ejemplares para resarcirse, con el producto de la venta, de los gastos de la edición, liquidándose el resto de esta a mitad con el autor.

Luis Astrana Marín [PSR1/6-232] muestra su descontento ante el cambio de las condiciones de pago por su edición de Quevedo el 10 diciembre 1929:

Desde luego, eliminadas las cláusulas 12 y 14, es decir, la entrega de mil pesetas mensuales mientras dure la edición y de cinco mil al firmarse el contrato [...] no me es posible hacer la edición; y mentira parece que, con su gran talento de Vd., se imaginara que sin esas condiciones se pueda llevar a cabo [...]. Usted comprenderá que de los errores que pueda haber cometido la Iberoamericana dando anticipos extraordinarios a personas que no la reportarán honra ni provecho, no voy a pagar yo, ni una edición de este fuste, las consecuencias. Es natural que la Junta de la CIAP haya querido poner coto a las complacencias con que principió, mas ahora pagarán justos por pecadores, y muchas empresas de importancia no podrán hacerse, porque esas reservas de anticipos debieron guardarse para estas ocasiones. Cerca de dos años hemos llevado hablando de la edición de Quevedo [...] sírvanle de consuelo las [obras] de Andrenio ${ }^{16}$, que esas sí que se van a vender... al peso.

Vicente Aleixandre [PSR1/7-103], el 14 de mayo de 1931, comenta:

Estos días te escribo para decirte que si mi libro no está materialmente tirándose (y supongo que no) será mejor que lo detengas (ibien detenido

${ }^{16}$ Seudónimo de Eduardo Gómez Baquero. 
viene estando!) porque prefiero en lugar de ese libro darte otro. Soy más fecundo poeta de lo que tú te suponías y tengo terminado un libro de verso que a mí me parece bastante interesante (no te rías). Y puesto que esta bendita CIAP me va a hacer un libro ahora, prefiero que sea el último que tengo, que está en verso y por tanto es más claro libro de poeta que el otro...

Vicente Huidobro [PSR1/5-202], que traduce para la editorial, expone las gestiones para conseguir una ilustración de Picasso [25 noviembre 1928].

Eduardo Barriobero [PSR1/5-459], el 4 abril 1929, presenta la obra de Pi i Margall:

Yo no soy un gran jurisconsulto; sigo siendo «El Abogado de los Pobres», y en eso me quedé; pero en cambio soy un hombre de lucha, a quien no destemplan los desaires ni embriagan los elogios. Puestas las cosas en ese plano, creo que podremos entendernos fácilmente [...]. Voy a ofrecerle lo que, a mi juicio, puede convenir extraordinariamente a la Editorial de su Dirección. La familia de Pi Margall me ha encargado de buscar un editor para Las nacionalidades, obra agotada y muy solicitada desde hace año y medio. ¿Quieren Vds. hacer la nueva edición?

Artemio Precioso [PSR1/6-228], el 6 diciembre 1929, acuciado por las deudas editoriales pide ayuda a PSR desde París.

\section{LOS ILUSTRADORES}

Miguel Mihura [PSR1/5-255], el 24 de diciembre de 1928, sugiere sus servicios como ilustrador:

Las ilustraciones de «La Novela de Hoy» las haría a cien pesetas, siempre que me dieran a ilustrar estas novelas con una frecuencia razonable, manifestándole que yo no solo puedo ilustrar novelas cómicas -por mi calidad de caricaturista- sino que también puedo hacer -en otro estilo nuevo- otra clase de novelas modernas. En cuanto a las portadas de libros, las haría al mismo precio (cien pesetas). Claro está que este precio, como el de $\mathrm{La}$ Novela de Hoy, oscilaría según el trabajo que me encargasen mensualmente, pues a mayor número de novelas menos cobraría. 
Por su parte, Rafael de Penagos [PSR1/5-258], el 25 de diciembre, hablando de los precios de sus ilustraciones, indica: «Cubiertas para libros a todo color, cien pesetas. Cubierta y diez ilustraciones para La novela de hoy, doscientas pesetas». Y Salvador Bartolozzi [PSR1/5259], el 28 de diciembre: «El precio de una ilustración de una Novela de Hoy (portada y diez dibujos) es doscientas cincuenta pesetas».

\section{LOS PREMIOS}

«Nuestros premios literarios, por su cuantía y por la seriedad de su organización, son algo inusitado en nuestras costumbres literarias y editoriales» [Catálogo general CIAP, 1930: 12].

La Asociación El Mejor Libro del Mes ${ }^{17}$, creada en 1923, fue un incentivo más de la editorial para con sus autores, y un eficaz instrumento de publicidad. En ella, un comité de expertos elegía el mejor libro editado cada mes. El asociado lo recibía mensualmente, junto a otros recomendados, al precio de cinco pesetas. La CIAP tenía mucho peso en la Asociación y se servía de ella para distribuir su catálogo editorial.

Ricardo Baeza [PSR1/6-127], secretario de la Asociación, se dirige a PSR el 1 de agosto de 1929:

Nos encontramos ante el espinoso dilema de tener que optar entre el libro de Azorín y el de Doña Concha [Espina]. Desgraciadamente, los dos son muy malos, pero no cabe duda que el de Azorín es de un mayor decoro literario y, desde luego, no sería justo posponer a Azorín a Doña Concha. Desgraciadamente, tampoco cabe duda de que el libro de Azorín es muy flojo, de que tiene mala atmósfera entre los del oficio donde apareció y de

${ }^{17}$ El comité de expertos que compone el Jurado lo constituyen Rafael Altamira, Eduardo Gómez Baquero, Ramón Pérez de Ayala, Gabriel Miró, José María Salaverría, Pedro Sainz Rodríguez, Enrique Díez-Canedo y Ricardo Baeza. En el discurso de creación de la sociedad se indica que «aunque generalmente se tenderá a que el mejor libro del mes sea de un autor español, cuando su valor excepcional lo justifique podrá designarse alguna traducción al español de obra extranjera». 
que seguramente habría de defraudar a la mayoría de los lectores, que podrían acusarnos de compadrazgo literario, respeto excesivo a los santones, etc. Así, Ayala y yo hemos pensado en una solución, que, sobre ser la más justa, evitaría las dificultades del dilema Azorín-Doña Concha, acallando de paso la susceptibilidad de nuestros autores nacionales. A saber: la designación como «mejor» de la novela de Remarque Sin novedad en el frente, explicando el fallo al público (de manera que pueda ofrecerse una dedada de miel a dichos autores nacionales) por la universalidad del libro de Remarque $[\ldots]$ y su índole moral y social, lo que hace deseable su máxima difusión. Por otra parte, en justicia, no cabe duda de que es el «mejor», con mucho, de los libros de junio, y que ningún lector podrá sentirse defraudado. Por último, no está mal que ayudemos a difundir este libro antimilitarista, y tan convincente, en esta época de dictadura. Salaverría y Gabriel Miró, consultados sobre el particular, se han adherido enseguida a nuestra idea [...]. (También, desde el punto de vista de CIAP, no cabe duda es preferible señalemos el libro de Remarque, del que tiene la exclusiva de venta, que el de Azorín, que es de «Biblioteca Nueva»).

\section{LA QUIEBRA}

El año de 1931 marcará el declive de la CIAP, y son muchos los que se manifiestan lamentando la situación: Luis Morales, Luis Méndez Albarrán, Aniceto de Castro, Alberto Nin Frías, Enrique Gosálvez, Javier Ortueta. Otros reclaman su liquidación: Emilio Orduña, Romero Flores, Jesús R. Coloma. La situación se prolongará hasta 1936, con correspondencia relativa a derechos de venta por parte de muchos autores, reclamaciones de manuscritos, etc.

El 7 de julio de 1932, Manuel Ortega [PSR1/8-129] comunica a PSR el escrito dirigido al gobernador del Banco de España, en una entrevista concedida por él,

a la cual acudieron los escritores que forman la comisión gestora, o sea Valle-Inclán, Fernández Flórez, Insúa, Hernández Catá, Francés, Martínez Sierra, Barriobero, Martín Luis Guzmán y Carretero. El Señor Carabias nos manifestó que el asunto pasaba ahora a la Comisión Jurídica Asesora, pero que fuese cual fuera la decisión de dicha Comisión, él no veía otra 
solución posible que la de aceptar el plan propuesto por la CIAP, y aprobado por sus autores.

Y el 30 de noviembre mantiene su optimismo [PSR1/8-234]:

Le remito tres notas sobre la situación de la CIAP. La primera de ellas se refiere muy concretamente a la situación judicial de la empresa, cuya suspensión de pagos está pendiente de la resolución de la Audiencia. La segunda es un estudio sobre la situación económica de la CIAP, en extremo favorable, como Vd. ve si se piensa en la gran crisis mundial que afecta en igual medida al negocio librero. La tercera de estas notas trata de la proposición que haremos en su día a la comisión liquidadora de los acreedores de Bauer.

\section{El 18 de marzo de 1933 prosiguen las conversaciones [PSR1/9-43]:}

Hemos llegado en principio a un acuerdo para solucionar el asunto CIAP, sobre la base de que renunciemos a la cuenta de participación y abonar el crédito en veintitantos años, haciendo una emisión de bonos sin interés. Ultimado este acuerdo Bauer y Cía., en la Audiencia mostrará su conformidad y quedará firme el acuerdo en la suspensión de pagos y ésta se levantará inmediatamente.

\section{El 13 de mayo de ese mismo año notifica la vista [PSR1/9-78]:}

Esta mañana se ha celebrado en la Audiencia la vista de la CIAP. Osorio ha estado realmente bien, haciendo un informe muy fundamentado en Derecho, que duró hora y media. Por los signos afirmativos de los Magistrados, pude advertir hasta qué punto estaban varios de ellos de acuerdo con la exposición de Osorio [...]. La impresión general era que teníamos ganado el asunto, pero yo no me fío mucho, dado el caciquismo que ejerce Sánchez Román en la Audiencia [...]. Desde luego, entablaremos inmediatamente el recurso de casación ante el Supremo, caso de que hayamos perdido esta vez.

Y el 18 de mayo [PSR1/9-80]:

Todavía no hay sentencia, pero tengo noticias de la Audiencia de que se reúnen mañana los magistrados para darla [...]. Tengo la impresión de que si neutralizamos la influencia de Sánchez Román tenemos ganado el asun- 
to, pues los magistrados que vacilan, están convencidos de que tenemos razón [...]. No deje de hacer las gestiones hoy mismo. Mañana sería tarde.

Dice Emilio Carrere en La Libertad (3 de marzo de 1933): «Desde hace un año la actividad editorial es nula. El libro sufre en estos instantes un denso oscurecimiento [...]. En esta hora negra de la profesión literaria, la catástrofe de la CIAP constituye la ruina del libro y de los desventurados y mansos literatos españoles».

El proceso judicial prosigue su marcha con lentitud. Y se reciben cartas de apoyo, como la de Luis Rodríguez de Viguri [PSR1/9-81], el 19 mayo 1933: «Es lamentable ver hundir una empresa cultural de tanta utilidad para la difusión del libro español, pero su letrado estoy seguro que aun encontrará medios de dilatar la ejecución de la sentencia».

Manuel Ortega no pierde la esperanza, y el 21 de junio de 1933 escribe a PSR [PSR1/9-101]:

$\mathrm{Al}$ fin hoy ha vencido la CIAP, después de una lucha tremenda para que nos diese la Audiencia el testimonio para entablar el recurso ante el Tribunal Supremo. Va muy bien el recurso, pues lleva dos votos reservados de dos Magistrados. Es decir, que el Supremo tiene que decidir entre tres sentencias, de ellas dos favorables a nosotros. Creemos que triunfaremos allá arriba y que quedará restablecido nuestro derecho. La vista se celebrará dentro de un año.

Y el 9 de diciembre del mismo año [PSR1/9-215]: «Lo del Supremo va adelante y urge que nos ocupemos del asunto, pues podemos ganarlo $[. .$.$] . Le ruego que recomiende eficazmente nuestro pleito,$ pues si lo perdemos nos van a molestar y a dar la lata. Y tengo la impresión de que, apretando un poco, lo ganaremos». Llegamos al 25 de enero del año 1934, y Manuel Ortega [PSR1/9-280] insiste, tratando de recurrir a cualquier medio: «No deje de la mano apretarles a los Sres. Goicoechea y Primo de Rivera para que recomienden al Señor Puebla el asunto de la CIAP».

Ya estamos a 23 de marzo de 1934, y Manuel Ortega [PSR1/9-350] informa: 
El 9 del próximo abril tendrá lugar en el Tribunal Supremo la vista del recurso de admisión del asunto CIAP [...]. Bien sabe que no ventilamos en esto la existencia de una empresa cualquiera, sino la de una entidad a cuya vida están adscritos intereses de buena parte de los escritores españoles. El recurso debe ser admitido para que estos intereses, unidos por su valor a los de la cultura patria, no se pierdan y puedan volver al auge que obtuvieron merecidamente con la CIAP [...]. Insisto en que únicamente deseamos que el Supremo conozca en toda su integridad la cuestión y resuelva en justicia.

El 5 de diciembre de 1934, Manuel Ortega [PSR1/10-95] trae malas noticias:

Ya hemos recibido la sentencia del Tribunal Supremo, que no admite el recurso que hemos interpuesto contra la resolución de la Audiencia en el expediente de la suspensión de pagos [...]. Y ya estamos prevenidos para afrontar la nueva situación que se nos plantea [...]. Yo estoy en negociaciones con la comisión liquidadora de la Casa Bauer y Cía...

El 27 de mayo de 1935 [PSR1/10-518], PSR informa por última vez sobre la situación de la CIAP:

Por la suspensión de pagos de la Casa Bauer y Cía., [la CIAP] tuvo a su vez ella que suspenderlos también. Acaba de ser levantada la suspensión y casi todos los acreedores [...] han convenido con nosotros particularmente [...] en cobrar sus créditos sin quita alguna, a medida que las posibilidades de la CIAP lo permitan; pero ha surgido un incidente con el abogado Señor Rodríguez Rivera que patrocina un crédito de 3 o 4.000 pesetas y que nos pide la quiebra con fines sospechosos. Este asunto está en el Juzgado número 1, el cual regente su Señor hermano y este Juzgado ha decretado la quiebra a la que nos hemos opuesto, ya que mal podíamos pagar el crédito del Señor Rivera estando en suspensión de pagos como estaba al instar la quiebra dicho Señor. Nosotros deseamos que se nos haga justicia y que el Juzgado resuelva favorablemente a nuestras pretensiones en el escrito oponiéndonos al auto $[\ldots]$. Con ello se salvaría esta obra cultural junto con los intereses de buena fe que nada pueden ganar con la quiebra y que sin ella cobrarían totalmente sus créditos. 
El 4 de junio, Manuel Ortega [PSR1/11-28], adjunta el acta de la reunión de acreedores. Todavía el 5 de junio PSR [PSR1/11-30] insiste en sus buenos deseos: «Es preciso que la CIAP se salve y vuelva a resurgir esa obra cultural que era la primera de España [...]. Si la tramitación judicial no va deprisa, creo que llegaremos a un acuerdo con Bauer y Cía. sin necesidad de mantener la quiebra, que salve tantos intereses hoy comprometidos». Finalmente no fue así.

\section{CONCLUSIÓN}

Las páginas finales del catálogo editorial de la CIAP de 1930 resumen lo que pretendió ser la Compañía Iberoamericana de Publicaciones:

La CIAP [...] aspira a labrar los cimientos de una profunda y verdadera compenetración de la cultura hispanoamericana, desea investigar nuestro pasado glorioso e impulsar nuestro progreso difundiendo la cultura por todos los medios. El libro español debe estar en proporción con la importancia histórica y vital de nuestra lengua y debe ser el instrumento eficaz de la cultura de nuestra raza y de la expansión de nuestro espíritu en el mundo.

Sin duda este complejo editorial inaudito en su tiempo sigue sorprendiéndonos por su alcance. Esta enorme empresa editorial pretendió abarcar todos los ámbitos del mundo del libro, y podemos decir que lo consiguió. Contó con una nómina de autores muy extensa, con un equipo de editores y traductores de primera fila, y con una dirección acertadísima. Fue una lástima que el proyecto quedara frustrado por problemas económicos. Su catálogo de publicaciones de 1930 es ejemplar, tanto por la variedad y calidad de sus títulos, como por su organización con buenos índices y su pulcritud editorial. Y sin duda, para conocer la historia de la CIAP se hace imprescindible la consulta del Archivo de Pedro Sainz Rodríguez, depositado en la FUE. 


\section{BIBLIOGRAFÍA}

CATÁlogo General (1930): Catálogo general, Madrid, CIAP.

COMPAÑÍA IBERO AMERICANA DE PUBLICACIONES (¿1932?): Cómo se ha hecho una gran empresa editorial y cómo pretenden deshacerla, Madrid, CIAP.

ESCRIBANo HeRnándeZ, Julio (1998): Pedro Sainz Rodríguez, de la Monarquía a la República, Madrid, FUE.

y HerRera NAVARRO, Jerónimo (2007-2015): Epistolario de don Pedro Sainz Rodríguez, Madrid, FUE.

FUSTER, Francisco (2015): «Semblanza de la Compañía Iberoamericana de Publicaciones (1924-1931)", en Biblioteca Virtual Miguel de Cervantes Portal Editores y Editoriales Iberoamericanos (siglos XIX-XXI).

Libros: boletín mensual de novedades, año XLIX, enero-diciembre 1930.

LÓPEZ-MORELL, Miguel Ángel y MOLINA ABRIL, Alfredo (2012): «La Compañía Iberoamericana de Publicaciones, primera gran corporación editorial en castellano», en Revista de Historia Industrial, 49/2: 111145.

SAINZ RodríGUEZ, Pedro (1978): Testimonio y recuerdos, Barcelona, Planeta.

SANTONJA, Gonzalo (1989): La República de los libros. El nuevo libro popular de la II República, Barcelona, Anthropos. 